\title{
Anthropocentrism of the Earth and Mankind in Modern World of Science and Technology
}

\author{
Y. V. Subba Rao \\ Jyotish, Dept of Jyotish, Rashtriya Sanskrit Vidyapeeth, Tirupati, Andhra Pradesh, India
}

Email address:

yvsubbarao2004@yahoo.com

\section{To cite this article:}

Y. V. Subba Rao. Anthropocentrism of the Earth and Mankind in Modern World of Science and Technology. Advances in Sciences and Humanities. Vol. 3, No. 6, 2017, pp. 76-81. doi: 10.11648/j.ash.20170306.11

Received: January 26, 2017; Accepted: February 16, 2017; Published: October 31, 2017

\begin{abstract}
Mankind regards itself as the most important and central factor in the universe. Technological advances in Astronomy have deprived mankind of anthropocentrism of his planet, the Earth. Mankind is now left to take an openminded view of our uniqueness or lack thereof in the universe with intensive search for intelligent life elsewhere in the universe to claim anthropocentrism or not. The significance of the paper is that search for intelligent life elsewhere in the universe is a futile exercise costing billions of dollars considering the astronomical factors involved vis $-a-v i s$ Veda which establishes that life in physical form exists only in this world in universe and there need be no apprehension of mankind's anthropocentrism.
\end{abstract}

Keywords: Earth-Like, Extra-Terrestrial Life, NASA, Claudius Ptolemy, Copernicus, Aryabhata, Hindu Mythology

\section{Introduction}

In India science and religion are not opposed fundamentally, as they are in the West. In addition, they are seen as parts of the same great search for truth and enlightenment that inspired the sages of Hinduism.

Mankind regards itself as the most important and central factor in the universe. We cannot afford to take an essentially anthropocentric, short-term view of the future. From an anthropocentric view in which we see our species as the ultimate achievement of evolution, other species look somewhat incomplete. When we assess animal intelligence, we tend to take a very anthropocentric view. But the truth is far from the real. Scientific researches and technological advances in astronomy gradually deprived the anthropocentrism of our earth in the universe thus pushing the mankind to the anthropocentric view of itself [1].

\section{Geocentric Model}

The Western world used to believe that the Earth was the centre of the universe. It was an idea that the ancient Greeks first proposed.

The geocentric model was developed thousands of years ago, by Greek philosophers and was the accepted model of the
Solar System for centuries. Geocentric actually means earth centered. This model is also called the Ptolemaic system in honour of the Greek scientist and philosopher Claudius Ptolemy, although the theory was around years before him. The geocentric model places the Earth at the center of the universe. This is indeed a unique position (Figure 1).

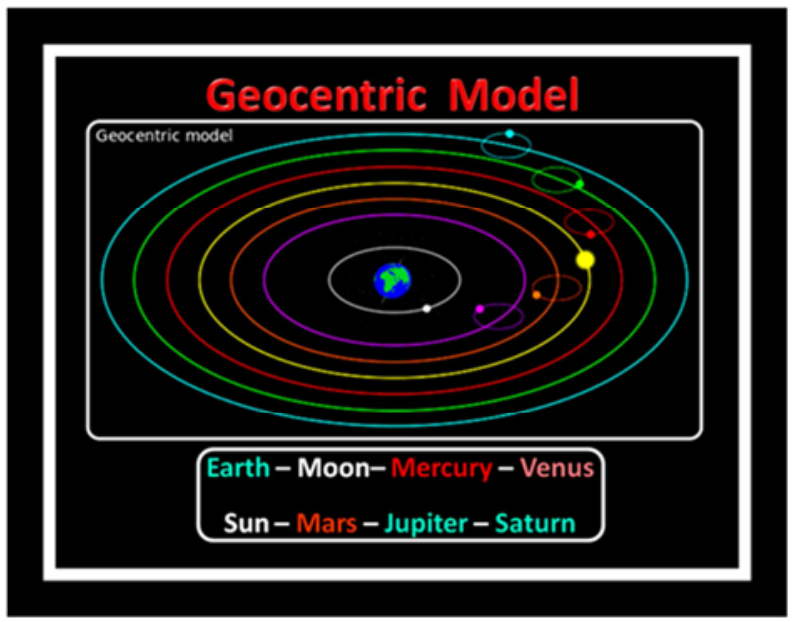

Figure 1. Geocentric Model. 


\section{Heliocentric Model}

The heliocentric model, which means sun centered, gradually replaced the geocentric model. This new system places the Sun at the center of the Solar System with the Earth and all the other planets orbiting it. This theory revolutionized everything because it reversed centuries of established opinion. Although, Āryabhatta propounded the heliocentric theory, thus predating Copernicus by almost one thousand years, his heliocentric theory may not have caused much of an impression on European astronomers as it could not reach them for want of of proper means of media or communication and as by then they had come to know of these facts through the observations of Copernicus and Galileo. The idea of a heliocentric model had been around as early as 400 A. D., it did not gain popularity until the 16th century (Figure 2).

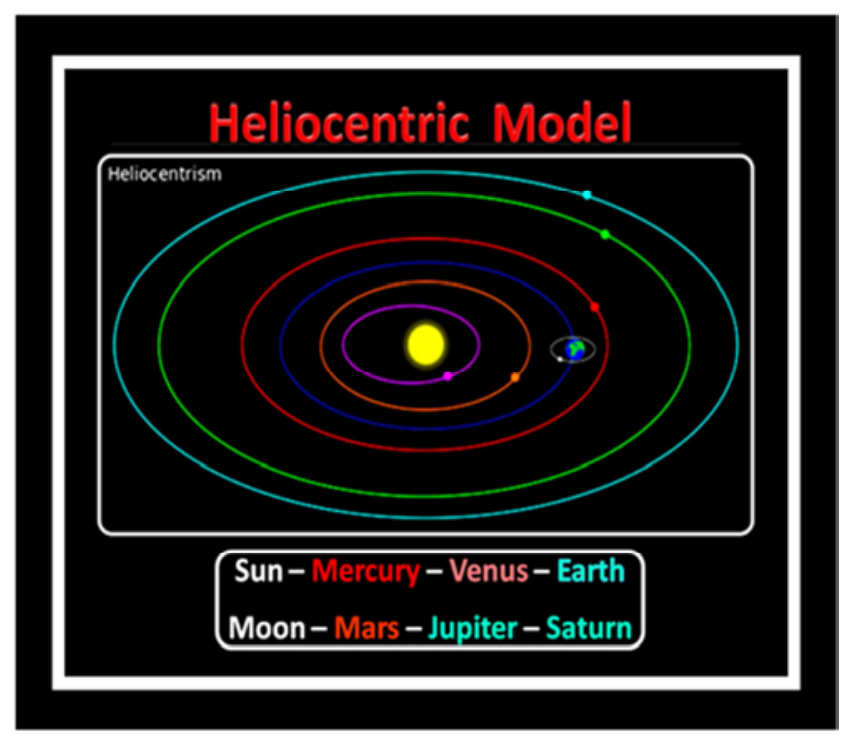

Figure 2. Heliocentric Model.

Modern science has recognized that we are not even the center of our own galaxy. With the advances of technology in Astronomy, the anthropocentric view of our Earth gradually diminished from the consideration so far held idea of it as the centre of our solar system; later, it is established that neither our solar system is the centre of our galaxy nor our galaxy is the centre of the universe. We do not have any similar evidence to suggest that we are not the centre of the universe. We do not have any evidence to suggest that we are. Such evidence is impossible at present because we cannot even be sure that the universe has a centre. If it is infinite, a unique central point has no meaning for every point is in some sense the centre.

However, astrophysicists know that we once incorrectly assumed ourselves to be the centre of the solar system and are wary of making the same mistake twice. It is with this, unbiased statistical reasoning that modern-day astronomers believe that we are not the centre of the galaxy of which our solar system is a member.

\section{First Our Galaxy}

"When we consider how small the Earth is in relation to the Milky Way, and then the Milky Way in relation to the universe, we are not even a speck of sand on a beach, nor a drop of water in the ocean" [2].

Our Solar System is located towards the edge of one of the Milky Way's outer spiral arms, known as the Orion Arm or Local Spur, about 25,000 to 28,000 light years from the galactic centre. The Milky Way galaxy is a barred spiral galaxy with a diameter of about 100,000 light-years and containing about 200 billion stars. Our Solar System is located towards the edge of one of the Milky Way's outer spiral arms, known as the Orion Arm or Local Spur, about 25,000 to 28,000 light years from the galactic centre (Figure 3). [3].

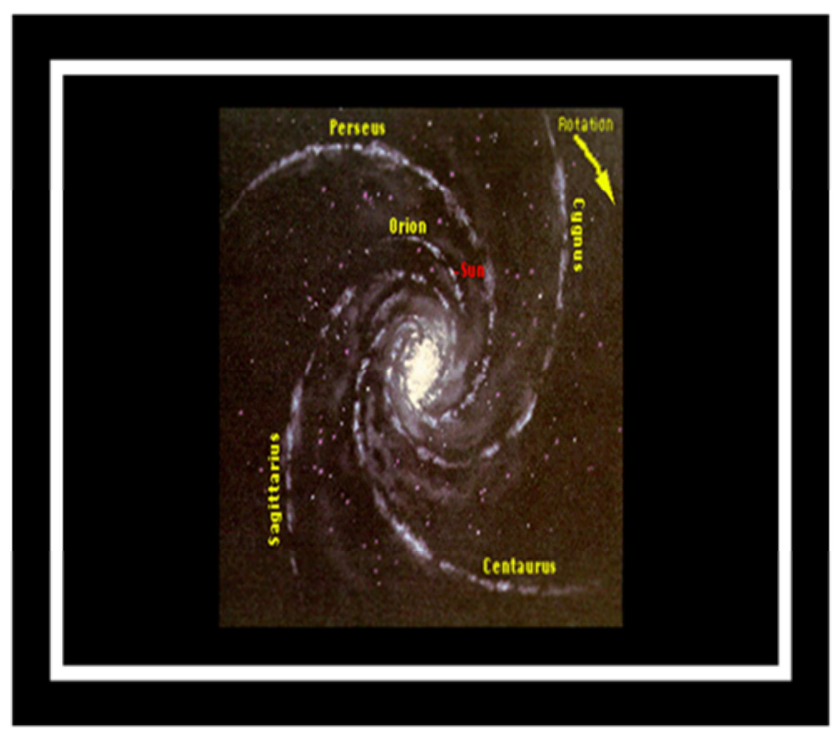

Figure 3. Our Solar System in relation to the Milky Way.

Our Solar System is located towards the edge of one of the Milky Way's outer spiral arms, the Orion Arm. The Milky Way is a spiral galaxy. We believe that it consists of a central bulge, 4 major arms, and several shorter arm segments. The Sun (and, of course, the rest of our solar system) is located near the Orion arm, between two major arms (Perseus and Sagittarius).

\section{Universe}

Scientists have known for some time that the Milky Way Galaxy is not alone in the Universe. In addition to our galaxy being part of the Local Group - a collection of 54 galaxies and dwarf galaxies - we are also part of the larger formation known as the Virgo Supercluster. So, one could say the Milky Way has a lot of neighbours [4].

Technological advances in Astronomy have deprived mankind of anthropocentrism of his planet, the Earth. Astronomers are now left to take an open-minded view of our uniqueness or lack thereof in the universe with intensive search for intelligent life elsewhere in the universe to claim 
anthropocentrism or not.

This experiment of fundamental research is one of purely academic in its nature serves no practical utility to mankind and on the other involves a huge budgetary provision of a nation's GDP.

\section{Mother Earth}

Earth had billions of years and countless environments to create life. The deposited building blocks of Life on Primordial Earth by the meteors and comets are protected and nourished by the earth. Earth is largely protected from the solar wind, a stream of energetic charged particles emanating from the Sun, by its magnetic field, which deflects most of the charged particles. That face of the earth having solar light is filtered of all harmful types of rays like UV rays and X-rays; a protective field for life to manifest on the earth was created. The above two stages can be deciphered from the modern geological point of view in tracing evolution of living matter. As much as that the earth is the only planet to give birth and protect life in its numerous forms make it really fit to be addressed as 'Mother Earth' and unique.

\section{Inhabitable Planets}

Moon, the Earth's satellite, is unique of its lunar magnetism in Astrophysics and its importance in Vedic Astrology, a Vedānga, one of the six limbs of Vedas that its orbit around the Earth provides conditions such as the tides and the seasons that were necessary for life to have evolved. There are many other parameters that were necessary for life to evolve elsewhere in our Solar System, extra Solar need to be satisfied.

How many Earth-like planets are out there? Do they support life and civilisation? Is there any extra-terrestrial intelligent life? So far there is no known intelligent life on other planets. It is certainly science if research is made in this direction to find answers to all these questions.

Population has already touched 1 billion bench mark. It may reach an alarming figure of double its size in another 50 years and is looking for an alternate for all its needs as our earth has become an over plundered planet.

\section{Potentially Inhabitable Planets}

What is inhabitable? What are the criteria for habitability? In defining them, we go by what we know of our Earth and extrapolate from there. Our Mother Earth serves as the model or guide. A planet then should have adequate water, energy sources and conditions that would allow the assembly of complex organic molecules.

\section{Extrapolation}

In the first instance, Stars are not habitable. The temperature and other conditions are too severe for any stable chemistry to occur. Hence, planets are the more likely hosts for life. In this, Earth is an excellent example for all what it has to be addressed as "Mother Earth". It is the right place orbiting the Sun. Sun is a stable source of energy for us. Its heat and temperature do not burn off any life forms on the planet Earth. While looking for other potentially habitable planets, while our Earth is the reference, we need to look at their position with respect to their Suns.

\section{Earth-Like Planets}

How many Earth-like planets are out there? Within a year five Earth-similar planets had been found in a habitable zone that could support life. It would seem that our planet and solar system may not be the unique vessel of life that we have for so long believed. Seth Shostak, a noted SETI astronomer, has estimated that in all likelihood there are at least 30,000 habitable worlds within 1000 light years of Earth [6]. 1. Earth-Like Planets

All the key ingredients for the development of life have been found to exist in space. NASA reported the presence of the amino acid glycine, a key ingredient in protein. This has been verified that the glycine came from space and was not due to earthly contamination [7]. Life building blocks of DNA are available as readymade kits in space and brought to the Earth by Meteorites [8]. As the evidence mounts, it becomes more and more clear that the ingredients needed for life are not unique to Earth. The possibility of alien life thriving somewhere other than Earth is now stronger than ever before.

\section{Intelligent Life on Other Worlds}

Although life may exist on other worlds, is there intelligent life; is there life that has reached our state of development or beyond? Has Intelligent Life Detected Us?

Life on Earth is not unique then it should be given that out of the millions and possibly billions of planets in our own galaxy, some of them have intelligent life. How advanced is that life? A logical deduction would be that a portion of that life is at least as advanced as ours and some of that life may be far advanced to ours.

\section{Other Worlds in Hinduism}

Hinduism defines fourteen worlds (not to be confused with planets) - seven higher worlds (heavens) and seven lower ones (underworlds). The earth is considered the lowest of the seven higher worlds. The higher worlds are the seven vyahrtis, viz. bhu, bhuvas, svar, mahas, janas, tapas, and satya (the world that is ruled by Brahma, the creator, the point of no return for the soul; and the lower ones (the "seven underworlds") orpaatalas are atala, vitala, sutala, rasātala, talātala, mahātala and pātala (Figure 4). 


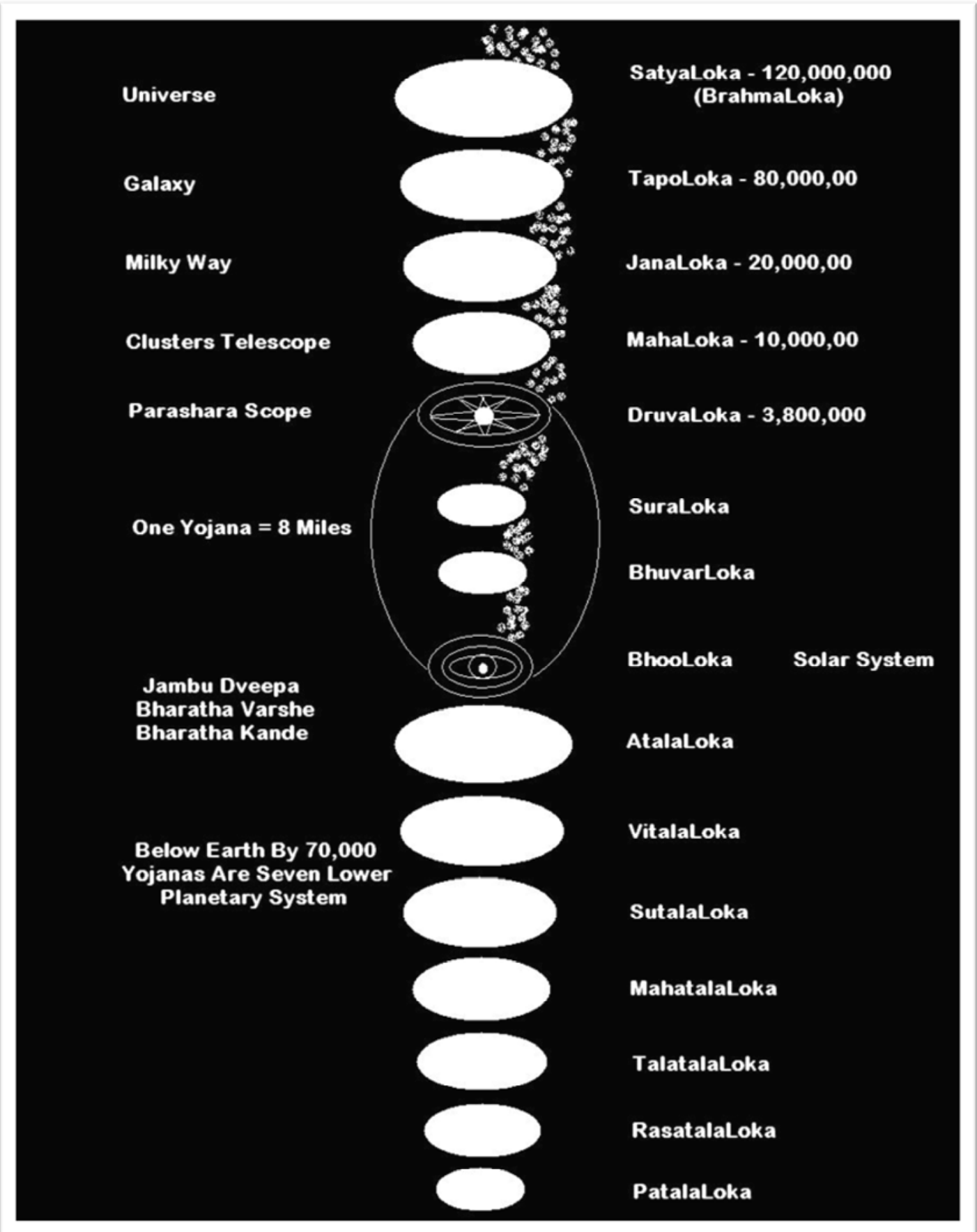

Figure 4. Different worlds both above and below the Earth according to Indian Mythology.

\section{Vedic Evolution of Human}

The following Table shows the sequential depiction of man evolving spiritually from primitive stage to a man bordering on divinity. The first three incarnations are change of form of species from one life form to another according to Darwinian Theory of evolution as a continuous process until the appearance of human indicated in the fourth incarnation. Darwinian Theory of evolution as a continuous process came to a grinding halt after the appearance of human. Change of species from one life form to another life form, scientists asserted it true and the process is encountered with excruciatingly painful delay [10] (Table No. 1). On the other hand, Hindu theory of evolution holds that even souls evolve. Evolution is a continuous change of form from one species of life to another species of life until human, and thereafter also it is a continuous process in the qualitative evolution of human beings from the primitive or stone-age man to a civilized one, slowly evolving and bordering on divinity and ultimately becoming an embodiment of divinity. 
Table 1. Evolution of soul and Ten Incarnations of Lord Vishnu

\begin{tabular}{|c|c|c|c|}
\hline SI. No & Incarnation & Expla-nation & Evolution on Spiritual Plane \\
\hline 1 & Matsya & Great Deluge & After 'Pralaya' it was great deluge. All animals that live only in water existed. \\
\hline 2 & Kurma & Land began to appear & $\begin{array}{l}\text { With efflux of time, water started evaporating and land began to appear. Animals that can live } \\
\text { both on land and in water came into being }\end{array}$ \\
\hline 3 & Varaha & Mud and slush formed & $\begin{array}{l}\text { In between water and land, there is slush and mud and animals that have affinity for slush } \\
\text { also came into being }\end{array}$ \\
\hline 4 & Narasimha & The Man-Lion never existed & It is symbolical of beastly instinct in man in the metaphorical sense \\
\hline 5 & Vamana & The dwarf man & The dwarfness is not related to the height but to the narrow mindedness of man \\
\hline 6 & Parasurãma & The man with the axe & It symbolises the revengeful attitude in man \\
\hline 7 & Rãma & Man bordering on divinity & Symbolises a perfect man with wisdom and equanimity of mind bordering on divinity \\
\hline 8 & Balarãma & Man with the Plough & He is portrayed with the plough. Human civilization has developed agriculture. \\
\hline 9 & Krishna & Divine & He is the embodiment of Divinity and ordainer of the Universe \\
\hline 10 & Kalki & Destroyer of foulness & $\begin{array}{l}\text { It symbolises his coming at a time when evil is the order of the day, and he is the saviour to } \\
\text { rid the world of its sufferings. This avatar is yet to come. }\end{array}$ \\
\hline
\end{tabular}

\section{Hindu Mythology}

All the worlds except the earth are used as temporary places of stay as follows: upon one's death on earth, the god of death (officially called 'Yama Dharma Raajaa' - Yama, the lord of justice) tallies the person's good/bad deeds while on earth and decides if the soul goes to a heaven and/or a hell, for how long, and in what capacity. Some versions of the religion state that good and bad deeds neutralize each other and the soul therefore is born in either a heaven or a hell, but not both, whereas according to another school of thought, the good and bad deeds don't cancel out each other. In either case, the soul acquires a body as appropriate to the worlds it enters. At the end of the soul's time in those worlds, it returns to the earth (is reborn as a life form on the earth). It is considered that only from the earth, and only after a human life, can the soul reach supreme salvation, the state free from the cycle of birth and death, a state of absolute and eternal bliss [11].

\section{Results}

The anthropocentrism of our Earth or in other words, our geographical uniqueness was gradually gone with the technological advances in Astronomy from the $4^{\text {th }}$ century onwards when the Sun replaced the Earth as the centre of our Solar System. Later, in about 100 years that modern science and Astronomy have recognized that neither we are even the centre of our own galaxy nor our galaxy is the centre of the Universe.

What remains of anthropocentrism for mankind is to verify and conform that no intelligent life exists in the Universe. Vedas, Hindu Philosophy and Hindu Mythology confirm the nonexistence of life in physical form anywhere in the Universe except on our Earth.

\section{Discussion}

We have remained the superior species on planet Earth and all our needs and beliefs have revolved around us. Religious beliefs extend even into the world of science. This fact should not disturb the scientists for, in the matter of any investigation and research where science could go thus far and no further, then religion affords the solution. The scientists of ancient Greece believed that the universe revolved around the Earth. Surely, we were the center of the universe. It was not until the $4^{\text {th }}$ century that the Aryabhatta's Heliocentric Theory known only in India and later until the $16^{\text {th }}$ century that the Copernican Theory moved the center of the universe from the Earth to the Sun. Science finally acquiesced and removed the Earth from the center of the universe with the comfort that now the Sun and our solar system would be the center of everything. It has only been in the last 100 years that modern science has recognized that we are not even the center of our own galaxy. Our geographical uniqueness was gone.

Nonetheless, our desire to be the centre of importance continues today. Everything was good - there was no evidence to argue against our unique position in the universe. Hinduism defines fourteen worlds (not to be confused with planets) seven higher worlds (heavens) and seven lower ones (underworlds). The earth is considered the lowest of the seven higher worlds. According to Hindu Philosophy, upon death the physical body 'Sthoola Sarira' perishes on the Funeral pyre and the astral body with the soul 'Sookshma Sarira' sets sail to other worlds depending on its past actions. After exhausting the fruits of their good actions in those worlds, it returns to the earth and is reborn as a life form on the earth. It is considered that only from the earth, and only after a human life, can the soul reach supreme salvation, the state free from the neverending cycle of birth and death, a state of absolute and eternal bliss. While all the key ingredients for the development of life have been found to exist in space, life in physical form of all beings including Humans and intelligent life exists only on this Earth (Bhuloka) [12]. This does not mean that those in other worlds are less intelligent; rather, those that live in higher worlds are more intelligent, pious and embodiment of spirituality. The opposite of these qualities rests with those that live in lower world. Our world is a junction of people in physical form with both these qualities. Sastra and science should collaborate and not contradict each other rather science should take a cue from sastra before attempting to crack any mysterious problem in the endeavour to make this world happy and peaceful. 
Astronomy provides safety to our planet. Our solar system was provided the giant planet Jupiter so that the Earth would not be constantly bombarded by asteroids. We need to protect our planet from being further plundered and destroyed let alone anthropocentrism. The budgetary allocation for research in the find of intelligent life elsewhere is better utilized in alleviating the suffering and the downtrodden so that the world can live in piece as one family without the distinction of 'haves' and 'have-nots'. This may also pave the way for total dismantling of nuclear weaponry and total demilitarization necessary to prevent wiping away the humanity from the surface of the globe, and also avert the real threat to the very existence of this planet.

\section{References}

[1] www.physlink.com/Education/AskExperts/ae614.cfm.

[2] www.universetoday.com/21914/the-closest-galaxy-to-themilky-way/Mar 4, 2015.
[3] starchild.gsfc.nasa.gov/docs/StarChild/questions/question18.h tml.

[4] www.physicsoftheuniverse.com/facts.html.

[5] Shostak, Seth. "A Bucketful of Worlds," Huffington Post, February 3, 2011.

[6] Elsila, Jamie. August 16, 2009. Meeting of the American Chemical Society in Washington, D. C.

[7] Callahan, (Aug 9, 2011), DNA Blocks found in Meteorites, Proceedings of the National Academy of Sciences of the United States of America.

[8] www.pinterest.com/pin/573223858797224723.

[9] en.wikipedia.org/wiki/Hindu_mythology.

[10] Robert Powell, "Something Intelligent This Way Comes", Sciknow Publications Ltd. JA 2014, 1 (1): 1-4 Journal of Astrobiology DOI: 10.12966/ja.05.01.2014.

[11] Rao, Y. V. S, Man is a Microcosm of the Macrocosm, the Universe, Journal of Advances in Philosophy Vol. 1. No. 1, 2015. 